\title{
In vitro anti-inflammatory, antioxidant and qualitative phytochemical evaluation of the Phytexponent preparation of selected plants
}

\section{Gervason Moriasi ( $\sim$ gmoriasi@outlook.com )}

Department of Medical Biochemistry, Medical School, Mount Kenya University, P.O BOX 342-01000Thika, Kenya. https://orcid.org/0000-0001-5604-9987

\section{Elias Nelson}

Department of Biological sciences, School of Pure and Applied Sciences, Mount Kenya University, P.O BOX 342-01000-Thika, Kenya.

\section{Epaphrodite Twahirwa}

Department of Pharmaceutical Chemistry and Pharmaceutics, School of Pharmacy, Mount Kenya University, P.O BOX 342-01000-Thika, Kenya.

\section{Research Article}

Keywords: Anti-inflammatory activity, Protein denaturation, Antioxidant activity, Phytexponent, Allium sativum, Triticum repens, Echinacea purpurea, Viola tricolor and Matricaria chamomilla, Phytochemicals

Posted Date: December 11th, 2020

DOI: https://doi.org/10.21203/rs.3.rs-124749/v2

License: (9) This work is licensed under a Creative Commons Attribution 4.0 International License. Read Full License 
In vitro anti-inflammatory, antioxidant and qualitative phytochemical evaluation of the Phytexponent preparation of selected plants Gervason Moriasi ${ }^{12^{*}}$, Elias Nelson ${ }^{3}$ and Epaphrodite Twahirwa ${ }^{4}$

${ }^{1 *}$ Department of Medical Biochemistry, Medical School, Mount Kenya University, P.O BOX 342-01000-Thika, Kenya.

${ }^{2}$ Department of Biochemistry, Microbiology \& Biotechnology, School of Pure and Applied Sciences, Kenyatta University, P.O BOX 43844-00100-GPO-Nairobi, Kenya.

${ }^{3}$ Department of Biological sciences, School of Pure and Applied Sciences, Mount Kenya University, P.O BOX 342-01000-Thika, Kenya.

${ }^{4}$ Department of Pharmaceutical Chemistry and Pharmaceutics, School of Pharmacy, Mount Kenya University, P.O BOX 342-01000-Thika, Kenya.

Corresponding Author: *Gervason Moriasi; Email: gmoriasi@outlook.com

\begin{abstract}
Oxidative stress is a critical etiologic factor and driver of inflammatory responses, witnessed in chronic and persistent conditions. The current anti-oxidative stress and anti-inflammatory drugs are associated with detrimental effects, high dependence, high costs, inaccessibility, among other drawbacks; therefore, a need for alternatives is imperative. Despite the remarkable potential of medicinal plants, there are scanty empirical studies on their pharmacologic efficacy. The Phytexponent is an alcoholic polyherbal preparation of Allium sativum, Triticum repens, Echinacea purpurea, Viola tricolor and Matricaria chamomilla. In complementary medicine, the Phytexponent is used to boost immunity, to treat inflammatory disorders, oxidative stress, blood pressure, diabetes, stress/depression, among other conditions. However, there is no sufficient scientific data to support these healing claims. Therefore, in the current study evaluated the in vitro anti-inflammatory, antioxidant activities and qualitative phytochemical composition of the Phytexponent. The in vitro anti-inflammatory activities were evaluated using the inhibition of protein denaturation and the human erythrocyte (HRBC) membrane stabilization techniques. Antioxidant activities were evaluated by the 1,1-diphenylpicryl-1-hydrazyl (DPPH) radical scavenging-, the hydroxyl radical scavenging- and catalase activities. Qualitative phytochemical screening was performed using standard procedures. The results showed a significantly higher percentage inhibition of heat-induced- and hypotonicity induced HRBC hemolysis by the Phytexponent at concentrations of $50 \%$ and $100 \%$, compared with the percentage inhibitions of etanercept $(\mathrm{p}<0.05)$. No significant differences in percentage inhibitions of protein denaturation were observed among concentrations of $12.5 \%, 25.0 \%, 50.0$ $\%, 100.0 \%$ of the Phytexponent and etanercept $(25 \mathrm{mg} / \mathrm{ml})(\mathrm{p}>0.05)$. Furthermore, the Phytexponent demonstrated high antioxidant activities against the DPPH- $\left(\mathrm{IC}_{50}=0.00733 \%\right)$ and the hydroxyl- $\left(\mathrm{IC}_{50}=0.716 \%\right)$ radicals in vitro. The Phytexponent recorded significantly higher catalase activities at concentrations of $1 \%$ and $0.1 \%$ than those recorded by ascorbic acid at similar concentrations. Qualitative phytochemical screening revealed the presence of phenols, flavonoids, tannins, among other antioxidant associated phytochemicals. The bioactivities of the Phytexponent reported herein, were attributed to the presence of these phytochemicals. Further studies to establish specific mode(s) through which the Phytexponent exerts in vitro anti-inflammatory and antioxidant effects are encouraged. Moreover, in vivo anti-inflammatory and antioxidant activities should be done to determine the replicability of these findings in vivo. Bioassay-guided isolation of compounds responsible for the reported bioactivities herein should be done.
\end{abstract}


Keywords: Anti-inflammatory activity, Protein denaturation, Antioxidant activity, Phytexponent, Allium sativum, Triticum repens, Echinacea purpurea, Viola tricolor and Matricaria chamomilla, Phytochemicals 


\section{Introduction}

Inflammation is an adaptive retort of the body to noxious stimuli like pathogens, toxins, chemicals, or physical harm (1). Research has demonstrated a strong relationship between oxidative stress and inflammation in living systems $(2,3)$. Furthermore, oxidative stress has been implicated as a critical instigator and triger of inflammatory responses (4). Therefore, homeostatic shifts in endogenous redox status impair the proper functioning of biomolecules, immune cells and immune molecules, thereby causing undesirable events (5-7). Oxidative stress in most cases has been linked to the genesis of most chronic and degenerative diseases that include atherosclerosis, cancer, diabetes, heart failure, liver injury, aging, chronic inflammation, neurodegenerative disorders, such as Alzheimer's disease, Parkinson's disease, Huntington's disease, and a plethora of other diseases (6-9).

Despite the phenomenal advances in conventional medicine, the current drugs prescribed for inflammation are associated with adverse side effects, are arguably inaccessible, unaffordable, and long-term use leads to tolerance and habituation (10-13). Because of this, there is an urgent need for complementary and alternative stratagems to curb oxidative stress and inflammation. Plants offer a viable and feasible alternative as they have for ages been an integral part of humankind in providing food, medicines, among other essential materials $(3,14)$.

The secondary metabolites (phytochemicals), which are synthesized by medicinal plants, play critical roles in modulating the body's redox status as well as inflammatory responses $(2,15,16)$. Interestingly, antioxidant phytochemicals promote health by scavenging free radicals, restoring the redox homeostasis, as well as enhancing the proper functioning of cellular biomolecules and cellular apparatus $(2,3,7,14)$. Additionally, the biological roles of these phytoactive plant-derived molecules in the body's signaling pathways via their interaction with cellular enzymes, specific receptors, as well as essential transcription factors, have been demonstrated (2). 
Phytexponent preparation consists of five medicinal plants, namely: Allium sativum (garlic), Triticum repens (couch grass), Echinacea purpurea (purple coneflower), Viola tricolor (wild pansy) and Matricaria chamomilla (chamomile). Allium sativum is used in traditional medicine to manage blood sugar levels, regulate blood pressure, cholesterol levels, as a stimulant of the immune system and as an anticancer medicine (17-19). Echinacea purpurea is utilized to boost immunity, manage high blood pressure, arthritis, and cancer (20-23). Triticum repens is active against diabetes mellitus and can lower cholesterol concentrations $(24,25)$. Viola tricolor has been shown to possess anticancer and anti-inflammatory properties $(26,27)$. The bioactive compounds of Matricaria chamomilla have been shown to exhibit antispasmodic, anxiolytic, anti-inflammatory, antimutagenic, and cholesterol-lowering effects (28-30). However, the pharmacologic efficacy of a combination of these herbals has not been validated empirically. Despite the application of the Phytexponent in the management of oxidative stress, inflammation among other disorders, no sufficient studies have been conducted to evaluate its pharmacologic efficiacy. The present study sought to evaluate the in vitro anti-inflammatory, antioxidant and qualitative phytochemical composition of the phytexponent as a potential therapy against oxidative stress and inflammation.

\section{Methodology}

\subsection{Source and Preparation of the Phytexponent}

The Phytexponent preparation (Pharmapath 27, Belgium; LOT NO:17E19) was purchased from a local herbal pharmacy and stored according to the manufacturer's recommendations. During experimentation, the Phytexponent was diluted in Normal saline to achieve various percentage concentrations for assay.

\subsection{Determination of in vitro anti-inflammatory activity}

\subsubsection{Determination of membrane stabilization activity}

The human erythrocyte membrane stabilization assay was performed as per the protocol of Sakat et al. (19) with minor modifications. Fresh blood was obtained from an individual with 
stable health and free from NSAIDs medication for the last two weeks prior to this study. This blood was then mixed with same mount of sterile Alseiver solution $(2 \%$ dextrose, $0.8 \%$ sodium citrate, $0.05 \%$ citric acid, and $0.42 \%$ sodium chloride in $100 \mathrm{ml}$ of triple-distilled water) and then centrifuged at $3000 \mathrm{rpm}$. The resultant packed human red blood cells after discarding the supernatant were rinsed with normal saline $(0.9 \%, \mathrm{pH} 7.0)$. The packed red blood cells were then reconstituted in normal saline $(0.9 \% \mathrm{NaCl})$ to yield $10 \% \mathrm{v} / \mathrm{v}$ Human Red Blood Cell (HRBC) suspension for assay.

\subsubsection{Hypotonicity induced hemolysis}

Different concentrations of the Phytexponent $(3.125 \%, 6.25 \%, 12.5 \%, 25.0 \%, 50 \%$, and $100 \%$ ), reference sample, and control were separately mixed with $1 \mathrm{ml}$ of phosphate buffer, $2 \mathrm{ml}$ of hyposaline and $0.5 \mathrm{ml}$ of the $\mathrm{HRBC}$ suspension. Etanercept at a concentration of 25 $\mathrm{mg} / \mathrm{ml}$ was used as a reference drug. All the assay mixtures were incubated at $37{ }^{0} \mathrm{C}$ for 30 minutes and centrifuged at $3000 \mathrm{rpm}$. The supernatant was aspirated, and its absorbance was measured by a Shimadzu-16001 (Tokyo Japan) UV-Vis spectrophotometer at $560 \mathrm{~nm}$. The percentage of hemolysis was estimated by assuming the hemolysis produced in control is $100 \%$. The percentage of erythrocyte membrane stabilization or protection was calculated by using the formula:

$\%$ Inhibition of HRBC Hemolysis $=\left[\frac{\text { Abs of control-Abs of sample }}{\text { Abs of control }}\right]$ X100

\subsubsection{Heat-induced hemolysis}

The $2 \mathrm{ml}$ reaction mixture comprised of $1 \mathrm{ml}$ phytoexponent at various study concentrations $(3.125 \%, 6.25 \%, 12.5 \%, 25.0 \%, 50 \%$, and $100 \%)$ or etanercept (reference drug at $25 \mathrm{mg} / \mathrm{ml}$ ) and $1 \mathrm{ml}$ of $10 \% \mathrm{v} / \mathrm{v}$ erthroceyte suspension. The negative control comprised of only the erythrocyte suspension and normal saline. The reaction mixtures in all tubes were incubated in athermostat set at $56{ }^{\circ} \mathrm{C}$ for half an hour. Post the incubation period, all the reaction mixtures 
were brought to room temperature by cooling under continously flowing tap water and then centrifuged at $2500 \mathrm{rpm}$ for 5 minutes. The resultant supernatants were specrtrophtometrically monitered at $560 \mathrm{~nm}$ and the absorbance recorded. All the tests for each sample was performed in triplicates. Assuming the haemolysis of the negative control as $100 \%(0 \%$ inhibition of hemolysis), the percentage inhibition of hemolysis by the Phytexpoent and referefence drug were determined as follows:

$\%$ Inhibition of HRBC Hemolysis $=\left[\frac{\text { Abs of control-Abs of sample }}{\text { Abs of control }}\right] \mathrm{X} 100$

\subsection{Determination of protein denaturation inhibition}

The anti-inflammatory activity was studied by inhibition of albumin denaturation technique, according to Mizushima \& Kobayashi, (33)and Sakat et al. (33) with minor modifications. The reaction mixture was consisting of test extracts $(3.125 \%, 6.25 \%, 12.5 \%, 25.0 \%, 50 \%$, and $100 \%$ ) and $1 \%$ aqueous solution of bovine albumin fraction. The sample extracts were incubated at $37^{\circ} \mathrm{C}$ for $20 \mathrm{~min}$ and then heated to $51^{\circ} \mathrm{C}$ for $20 \mathrm{~min}$, after cooling the samples, the turbidity was measured at $660 \mathrm{~nm}$. Etanercept at a concentration of $25 \mathrm{mg} / \mathrm{ml}$ was used as a reference drug. The experiment was performed in triplicate. The percentage of inhibition of protein denaturation was calculated as follows:

$\%$ inhibition of protein denaturation $=\left[\frac{\text { Abs of Control-Abs of Sample }}{\text { Abs of control }}\right] \times 100$

\subsection{Determination of in vitro antioxidant activities}

\subsubsection{The DPPH radical scavenging activity}

The DPPH free radical scavenging activity of the Phytexponent preparation was performed as described by Brand-Williams \& Berset (34) and Ruiz-Terán et al. (35) with some modifications. The different concentrations of $100 \%, 10 \%, 1 \%, 0.1 \%$, and $0.01 \%$ of the Phytexponent preparation and the ascorbic acid were obtained by diluting the stock solutions in methanol. Into differently labeled test-tubes, $2.5 \mathrm{ml}$ of the different concentrations of 
Phytexponent preparation or Ascorbic acid were added, followed by $1 \mathrm{ml}$ of $0.3 \mathrm{mM}$ methanolic solution of DPPH. The mixtures in all the test-tubes were then mixed by careful shaking of the test-tubes and then incubated for 15 minutes in an opaque area under room temperature. The absorbance was then recorded at $517 \mathrm{~nm}$ against methanol as the blank solution using a microprocessor UV-Vis double beam spectrophotometer. The control solution consisted of $2.5 \mathrm{~mL}$ of DPPH and $1 \mathrm{~mL}$ of methanol without phytexponent preparation or Ascorbic acid. The percentage of free radical scavenging activity was calculated from the following equation.

$$
\% \text { Radical scavenging Activity }=\left[\frac{\text { Abs of Control-Abs of Sample }}{\text { Abs of control }}\right] \text { X100 }
$$

\subsubsection{Hydroxyl radical scavenging activity}

The hydroxyl radical scavenging activity of the phytexponent preparation was determined by adopting the protocol of Klein et al. (36) with minor modifications. The phytexponent preparation and reference antioxidant (L-Ascorbic acid) were diluted in normal saline to yield the different woking concentrations of $100 \%, 10 \%, 1 \%, 0.1 \%$, and $0.01 \%$. Into the different test-tubes as per the different concentrations, the reaction mixture summing up of $2.4 \mathrm{ml}$ of phosphate buffer (pH7.8), $90 \mu 1$ of $1 \mathrm{mM} 1,10$-phenanthroline, $150 \mu 1$ of $0.1 \mathrm{mM}$ Hydrogen peroxide, $60 \mu \mathrm{l}$ of $1 \mathrm{mM}$ Irion (III) chloride were added followed with $1.5 \mathrm{ml}$ of Phytexponent preparation and L-Ascorbic acid into the respective test-tubes. The controls contained all the reagents except the test sample (Phytexponent preparation) and the standard (L-Ascorbic acid). The reaction mixtures in all the test-tubes were carefully shaken and then incubated for five minutes under room temperature. The absorbances were measured at $560 \mathrm{~nm}$, and the percentage radical scavenging activity obtained from the formula:

$\%$ Radical scavenging Activity $=\left[\frac{\text { Abs of Control-Abs of Sample }}{\text { Abs of control }}\right]$ X100 


\subsubsection{Determination of catalase enzyme activity assay}

In this study, the method of Aebi (37) and modified by Atawodi (38) was followed. Briefly, 10 $\mu 1$ of serum was added to be added into test tubes containing $2.80 \mathrm{ml}$ of $50 \mathrm{mM}$ potassium phosphate buffer in different each at a time. Then, $100 \mu 1$ of the Phytexponent preparation in the concentrations of $1,0.1,0.01$ and $0.001 \%$ were added into the specific test tubes in triplicate. The reaction process was initiated upon the addition of $100 \mu 1$ of freshly prepared 30 $\mathrm{mM}$ hydrogen peroxide to the reaction mixture, and the decomposition rate of hydrogen peroxide was spectrophotometrically monitored at $240 \mathrm{~nm}$ for 3 minutes at intervals of 1 min on a UV-VIS spectrophotometer.

\subsection{Qualitative phytochemical screening of the Phytexponent}

Qualitative phytochemical analysis for phenols, flavonoids, steroids, terpenoids, glycosides, alkaloids, tannins, saponins and anthroquinones was performed according to the methods followed by by Moriasi et al. $(39,40)$.

\subsection{Data management and statistical management}

In vitro, anti-inflammatory, and antioxidant activities' data were first tabulated on a spreadsheet using Excel (Office 365). The data was then exported to Minitab software version 19.2 for analysis. The descriptive analysis was performed, and the values were then presented as $\bar{x} \pm S E M$. One-Way ANOVA was performed to determine statistical significance among groups followed by Tukey's test for pairwise comparisons and separation of means. Comparisons between independent treatments were made using the Unpaired student t-test at a.05. Means with $\mathrm{p}<0.05$ were considered statistically significant. Qualitative Phytochemical screening data was just tabulated. The results were presented in tables.

\subsection{Ethical Considerations}


This study was conducted as per the ethical guidelines set out by the Scientific Research Ethics Review Committee of Mount Kenya University.

\section{Results and Discussion}

\subsection{In vitro anti-inflammatory activity of the Phytexponent preparation}

During inflammation, digestive lysosomal enzymes are secreted to the inflamed site to counter the invader (41). Consequently, stabilization of the lysosomal membrane helps to either delay or decrease the release of proteases among other mediators, thereby decreasing inflammation $(32,42)$. Since the human red blood cell (HRBC) membrane is analogous to that of the lysosome, a plant extract or compound that can inhibit hypotonicity-induced or heat-induced HRBC hemolysis can stabilize lysosomal membrane, thus averting its lysis leading to reduced inflammation $(32,43)$.

Table 1 presents the results for the inhibition of hypotonicity and heat-induced HRBC hemolysis by the Phytexponent and the etanercept. The results showed a concentrationdependent increase in inhibition of HRBC hemolysis by the Phytexponent under hypotonicity and heat stress (Table 1).

In the hypotonicity induced HRBC hemolysis, the percentage inhibition of HRBC hemolysis recorded at $100 \%$ concentration of the Phytexponent was significantly higher compared with the percentage inhibition at lower concentrations of $3.125 \%$ and $6.25 \%(p<0.05$; Table 1$)$. However, at concentrations, $3.125 \%$ and $6.25 \%$ of the Phytexponent, no significant difference in the percentage inhibition of the hemolysis of the HRBC was observed $(p>0.05)$. Interestingly, the percentage inhibitions of hypotonicity-induced HRBC hemolysis caused by the Phytexponent at concentrations of $50 \%$ and $100 \%$ were significantly higher than the percentage inhibition caused by the reference drug (etanercept) $(\mathrm{p}<0.05$; Table 1$)$. 
Besides, a positive concentration-dependent increase in percentage inhibition of heat-induced HRBC hemolysis was depicted by the Phytexponent (Table 1). The percentage inhibition of heat-induced HRBC hemolysis by the Phytexponent at a concentration of $100 \%$ was significantly higher than the percentage inhibitions obtained at the other concentrations $(\mathrm{p}<0.05 ;$ Table 1$)$.

Remarkably, the percentage inhibitions of heat-induced HRBC hemolysis recorded by the Phytexponent at concentrations of $50 \%$ and $100 \%$ were significantly higher than the percentage inhibition caused by etanercept, the reference drug $(\mathrm{p}<0.05$; Table 1$)$. However, no significant difference in percentage inhibition of heat-induced hemolysis was observed between etanercept and the Phytexponent at concentrations of $12.5 \%$ and $25 \%$ (p>0.05; Table 1).

Table 1: Inhibition of hypotonicity-induced and heat-induced HRBC hemolysis by the Phytexponent

\begin{tabular}{llll}
\hline Treatment & Concentration & $\begin{array}{l}\text { \% Inhibition of } \\
\text { Hypotonicity-induced } \\
\text { HRBC hemolysis }\end{array}$ & $\begin{array}{l}\text { \% Inhibition of Heat- } \\
\text { induced HRBC } \\
\text { hemolysis }\end{array}$ \\
\hline Phytexponent (\%) & 3.125 & $32.63 \pm 2.15^{\mathrm{f}}$ & $21.75 \pm 1.50^{\mathrm{f}}$ \\
& 6.25 & $37.07 \pm 0.36^{\mathrm{f}}$ & $43.56 \pm 1.30^{\mathrm{e}}$ \\
& 12.50 & $56.49 \pm 0.99^{\mathrm{e}}$ & $48.68 \pm 0.32^{\mathrm{d}}$ \\
& 25.00 & $65.07 \pm 0.35^{\mathrm{d}}$ & $55.24 \pm 0.10^{\mathrm{c}}$ \\
& 50.00 & $81.80 \pm 0.13^{\mathrm{b}}$ & $71.97 \pm 1.31^{\mathrm{b}}$ \\
& 100.00 & $92.23 \pm 0.13^{\mathrm{a}}$ & $92.44 \pm 0.41^{\mathrm{a}}$ \\
Etanercept & 25 & $71.74 \pm 0.33^{\mathrm{c}}$ & $50.87 \pm 0.36^{\mathrm{cd}}$ \\
\hline (Enbrel) $(\mathrm{mg} / \mathrm{ml})$ & & & \\
\hline
\end{tabular}

Values are presented as $\bar{x} \pm S E M$; Means with different superscript alphabets within the same column are significantly different among themselves (One-Way ANOVA followed by Tukey's test; $\mathrm{p}<0.05$ ).

These results show a great potential of the Phytexponent in the management of inflammatory conditions in the body. Studies have shown that extracts that stabilize the hypotonicity- and heat-induced $\mathrm{HRBC}$ hemolysis can be good candidates for in vivo studies and subsequent drug development $(5,44)$. 


\subsection{In vitro inhibition of protein denaturation by the Phytexponent}

Protein denaturation involves the destruction of the tertiary and secondary structures of proteins. The denaturation is as a result of the disruption of the forces that hold these structures together when subjected to external stress or compounds, such as strong acids or bases, concentrated inorganic salts, organic solvents, or heat (45-49). Most biological proteins lose their biological function when denatured, leading to a myriad of inflammatory conditions $(49,50)$.

Denaturation of proteins by either the pyretic state or proteases leads to tissue injury delayed wound healing, organ dysfunction, among other associated chronic diseases like rheumatoid arthritis (51). The production of autoantigens in certain arthritic diseases may be due to the denaturation of proteins responsible for the autoimmune responses that result in rheumatoid arthritis $(42,51)$.

As part of the investigation on the mechanism of the anti-inflammation activity, the ability of the Phytexponent to inhibit the denaturation of bovine serum albumin protein was studied with etanercept as a reference drug $(31,33)$.

The results showed no significant differences in percentage inhibitions of protein denaturation among the Phytexponent concentrations $(12.5 \%, 25 \%, 50 \%$ and $100 \%)$ and etanercept (25 $\mathrm{mg} / \mathrm{ml})(\mathrm{p}>0.05$; Table 2). However, at concentrations of $3.125 \%$ and $6.25 \%$, significantly lower percentage inhibitions of protein denaturation were observed $(\mathrm{p}<0.05$; Table 2$)$.

Table 2: In vitro inhibition of protein denaturation by the Phytexponent

\begin{tabular}{lll}
\hline Treatment & Concentration & \% Inhibition of Protein denaturation \\
\hline Phytexponent (\%) & 3.125 & $-340.70- \pm 12.50^{\mathrm{c}}$ \\
& 6.25 & $5.50 \pm 1.30^{\mathrm{b}}$ \\
& 12.50 & $65.67 \pm 0.67^{\mathrm{a}}$ \\
& 25.00 & $79.68 \pm 0.19^{\mathrm{a}}$ \\
& 50.00 & $89.23 \pm 0.23^{\mathrm{a}}$ \\
& 100.00 & $91.65 \pm 0.19^{\mathrm{a}}$ \\
Etanercept (Enbrel) $(\mathrm{mg} / \mathrm{ml})$ & 25 & $87.11 \pm 0.68^{\mathrm{a}}$ \\
\hline
\end{tabular}

Values are presented as $\bar{x} \pm S E M$; Means with similar superscript alphabet are not significantly different among themselves (One-Way ANOVA followed by Tukey's test; $p>0.05$ ). 
Research has shown that an extract or compound capable of inhibiting protein denaturation is a potent anti-inflammatory agent $(49,51)$. From the obtained results, the Phytexponent significantly inhibited heat-induced bovine serum albumin denaturation denoting its potential as an anti-inflammatory remedy $(43,51)$.

Moreover, the probable mechanism through which the Phytexponent may have inhibited protein denaturation could be through the stabilization of electrostatic, hydrogen, hydrophobic, and disulfide bonding in the protein structure (32) (49). Indeed, various anti-inflammatory agents, including non-steroidal anti-inflammatory drugs, have been found to prevent protein denaturation besides preventing prostaglandin synthesis (52).

Furthermore, the tumor necrosis factor $\alpha$ (TNF- $\alpha$ ) plays a central role in inflammatory processes, including the induction of collagen- and cartilage-degrading metalloproteinases, which denature tissues $(5,43,53)$. Also, the TNF $\alpha$ triggers the synthesis of prostaglandins among other pro-inflammatory mediators, which all add up to the detriment of body tissues $(1,54)$.

As a result, the inhibition of TNF $\alpha$ by pharmacologic agents like etanercept has been perceived as an effective therapy for inflammatory conditions $(53,55)$. Therefore, it is anticipated that one possible mechanism through which the Phytexponent exerted its effects could be through the inhibition of TNF $\alpha$, just like the reference drug (etanercept).

\subsection{In vitro antioxidant activities}

\subsubsection{In vitro DPPH radical scavenging activity of the Phytexponent}

Plants have, for long, been used by humans as sources of medicines to manage various ailments (56-59). The widely acknowledged mechanism of bioactivity of medicinal plants is through the amelioration of oxidative stress $(60,61)$. This bioactivity is due to various antioxidant phytochemical compounds, which work is complex mechanisms to restore redox homeostasis in body cells $(7,39,62-64)$. 
The link between oxidative stress and inflammation has been explored extensively $(16,65)$. Antioxidant therapy has been proposed as the most viable and practical approach to preventing and reversing inflammatory processes $(2,14,66)$. Given this, we studied the in vitro DPPH radical scavenging activity of the Phytexponent as a measure of its antioxidant capacity (BrandWilliams \& Berset, 1995; Ruiz-Terán et al., 2008)

The results showed that the percentage of radical scavenging activities produced by the Phytexponent at concentrations of $0.01 \%, 0.1 \%$, and $1 \%$ were not significantly different ( $p>0.05$; Table 3). However, significantly higher percentage radical scavenging activities were observed at the Phytexponent concentration of $10 \%$ and $100 \%$ compared with those produced at concentrations $0.01 \%, 0.1 \%$, and $1 \%(\mathrm{p}<0.05$; Table 3$)$.

On the other hand, no significant differences among the percentage free radical scavenging activities generated by the L-Ascorbic acid at a concentration of $0.01 \%, 0.1 \%$, and $1 \%$, and between $10 \%$ and $100 \%$ were noted ( $\mathrm{p}>0.05$; Table 3 ). However, the percentage of radical scavenging activities produced by L-ascorbic acid at concentrations $10 \%$ and $100 \%$ were significantly higher than those obtained at lower concentrations $(\mathrm{p}<0.05$; Table 3$)$.

Additionally, the concentration required to scavenge $50 \%$ of the DPPH radical $\left(\mathrm{IC}_{50}\right)$ was calculated from the plot of concentration against the percentage of radical scavenging activity.

The Phytexponent preparation and L-ascorbic acid had the $\mathrm{IC}_{50}$ values of $0.00733 \%$ and $0.00275 \%$, respectively.

Table 3: In vitro DPPH free radical scavenging activity of the Phytexponent

\begin{tabular}{lll}
\hline Concentration (\%) & \multicolumn{2}{c}{ \% DPPH Radical Scavenging Activity } \\
\cline { 2 - 3 } & Phytexponent & L-Ascorbic acid \\
\hline 0.01 & $68.06 \pm 0.92^{\mathrm{cA}}$ & $67.71 \pm 0.80^{\mathrm{bA}}$ \\
0.1 & $70.90 \pm 1.85^{\mathrm{cA}}$ & $68.06 \pm 0.92^{\mathrm{bA}}$ \\
1 & $71.34 \pm 1.95^{\mathrm{cA}}$ & $70.68 \pm 1.08^{\mathrm{bA}}$ \\
10 & $80.45 \pm 0.30^{\mathrm{bB}}$ & $94.09 \pm 3.56^{\mathrm{aA}}$ \\
100 & $89.69 \pm 0.35^{\mathrm{aB}}$ & $99.25 \pm 0.08^{\mathrm{aA}}$ \\
\hline $\mathrm{IC}_{50}$ & 0.00733 & 0.00275 \\
\hline
\end{tabular}


Values are presented as $\bar{x} \pm S E M$; Means with similar lowercase superscript alphabet within the same column are not significantly different (One-Way ANOVA followed by Tukey's test; $p>0.05$ ), while values with similar uppercase superscript alphabet across the same row are not significantly different at $\alpha_{0.05}$ (Unpaired student t-test; $\mathrm{p}>0.05$ )

Research has indicated that higher the percentage of DPPH radical scavenging activity correlates to higher antioxidant activity (67-69). From the obtained results, the Phytexponent was considered a potent DPPH radical scavenger. Furthermore, an appraisal criterion of Blois (67) and Fidrianny et al. (70) was used to grade the antioxidant activity of the Phytexponent. Based on this criterion, the low $\mathrm{IC}_{50}$ value of the Phytexponent obtained in this study indicates remarkable antioxidant capacity (70). The observed antioxidant effects could be due to the free radical neutralizing ability or the transfer of either a hydrogen atom or electron, which stabilize the redox equilibrium (71).

\subsubsection{In vitro hydroxyl radical scavenging activity of the Phytexponent}

Research has shown that excessive hydroxyl radicals have deleterious effects in the body ranging from increased fibrinolysis, sulfitolysis, destabilized membranes leaking to leakage, cross-linking of DNA, among others $(32,42)$. Furthermore, hydroxyl radicals induce major pathogenies biological membrane phospholipids in addition to their demonstrable reactivity with unsaturated fatty acids and ferrous $(32,42,43)$. These radicals trigger cascade reactions that alter cell integrity leading to a continuum of human pathologic conditions. These events have been implicated in neurodegenerative disorders, cancer, diabetes mellitus, arthritis, among other chronic illnesses. Hence, the current study sought to evaluate the hydroxyl radical scavenging activity of the Phytexponent (36).

The results showed a positive concentration-dependent increase in percentage hydroxyl radical scavenging activities for both the Phytexponent and L-ascorbic acid with significant 
differences $(p<0.05$; Table 4). Moreover, no significant differences between the percentage hydroxyl radical scavenging activities recorded by the Phytexponent and L-ascorbic acid at concentrations of $0.1 \%, 1 \%$, and $100 \%$ (p>0.05; Table 4). However, significantly higher percentage hydroxyl radical scavenging activities were produced by L-ascorbic at concentrations of $0.01 \%$ and $10 \%$ compared with those generated by the Phytexponent at similar concentrations $(\mathrm{p}<0.05$; Table 4$)$.

Moreover, the concentrations of the Phytexponent and L-ascorbic acid required to scavenge 50 $\%$ of the hydroxyl radicals $\left(\mathrm{IC}_{50}\right)$ were determined in this study. The $\mathrm{IC}_{50}$ values were $0.588 \%$ for L-ascorbic and $0.716 \%$ for the Phytexponent (Table 4).

Table 4: In vitro hydroxyl radical scavenging activity of the Phytexponent

\begin{tabular}{lll}
\hline Concentration (\%) & \multicolumn{2}{c}{$\%$ Hydroxyl radical scavenging activity } \\
\cline { 2 - 3 } & Phyt exponent & L-Ascorbic acid \\
\hline 0.01 & $14.60 \pm 0.40^{\mathrm{eB}}$ & $28.54 \pm 1.04^{\mathrm{eA}}$ \\
0.1 & $42.00 \pm 1.00^{\mathrm{dA}}$ & $44.30 \pm 0.03^{\mathrm{dA}}$ \\
1 & $53.75 \pm 0.75^{\mathrm{cA}}$ & $56.15 \pm 0.04^{\mathrm{cA}}$ \\
10 & $60.75 \pm 1.25^{\mathrm{bB}}$ & $70.00 \pm 0.22^{\mathrm{bA}}$ \\
100 & $73.15 \pm 0.85^{\mathrm{aA}}$ & $76.00 \pm 0.30^{\mathrm{aA}}$ \\
\hline $\mathrm{IC}_{50}$ & 0.716 & 0.588 \\
\hline
\end{tabular}

Values are presented as $\bar{x} \pm S E M$; Means with similar lowercase superscript alphabet within the same column are not significantly different (One-Way ANOVA followed by Tukey's test; $p>0.05$ ), while values with similar uppercase superscript alphabet across the same row are not significantly different at $\alpha_{0.05}$ (Unpaired student t-test; $\mathrm{p}>0.05$ )

Based on the results, the low $\mathrm{IC}_{50}$ value depicted by the Phytexponent demonstrated the remarkable antioxidant activity as per the criterion of Fidrianny et al. (70). Perhaps, the antiinflammatory efficacy reported herein is due to the antioxidant activity (14)

Studies have shown that the beneficial effects of plant-derived hydroxyl scavengers could be through lipid modification by reducing the unsaturation level at double bonds (71). Additionally, the presence of antioxidant phytocompounds works to thwart oxidative stress, thereby alleviating the underlying or associated health complications $(71,72)$. 


\subsubsection{Effects of the Phytexponent on in vitro catalase enzyme activity}

Catalase is a ubiquitous endogenous enzyme that catalyzes the disintegration of hydrogen peroxide, a toxic aerobic metabolism reactive oxygen species, which drives oxidative stress pathology (73-77) This enzyme plays critical roles in quenching and prevention of reactive oxygen species build-up, thereby ensuring redox homeostasis. In light of this, we investigated the effects of the Phytexponent on catalase enzyme activity in vitro $(37,38)$.

The results showed no significant difference in catalase enzyme activity at 0.001 and $0.01 \%$ of the Phytexponent $(\mathrm{p}>0.05$; Table 5). Similarly, the catalase enzyme activities at concentrations of $0.1 \%, 0.01 \%$, and $0.001 \%$ of L-ascorbic acid were not significantly different ( $p>0.05$; Table 5). However, the catalase enzyme activities recorded at a concentration of $1 \%$ both the Phytexponent and L-ascorbic acid were significantly higher than catalase enzyme activities recorded at all the other concentrations $(\mathrm{p}<0.5$; Table 5)

Furthermore, a comparison between the catalase activities produced at each of the studied concentrations was performed. The results showed no significant differences in catalase enzyme activities between the Phytexponent and L-ascorbic acid at concentrations of $0.001 \%$ and $0.01 \%(\mathrm{p}>0.05$; Table 5$)$. However, the catalase enzyme activity recorded at $0.1 \%$ and 1 $\%$ of the Phytexponent were significantly higher than those recorded at similar concentrations of L-ascorbic acid ( $<<0.05$; Table 5).

Table 5: Effects of the Phytexponent on in vitro catalase enzyme activity

\begin{tabular}{lll}
\hline Concentration (\%) & \multicolumn{2}{c}{ Catalase enzyme activity (u/mg protein) } \\
\cline { 2 - 3 } & Phytexponent & L-ascorbic acid \\
\hline 1 & $62.54 \pm 1.71^{\mathrm{aA}}$ & $54.82 \pm 0.12^{\mathrm{aB}}$ \\
0.1 & $56.95 \pm 0.23^{\mathrm{bA}}$ & $45.57 \pm 0.74^{\mathrm{bB}}$ \\
0.01 & $44.74 \pm 0.03^{\mathrm{cA}}$ & $44.72 \pm 0.85^{\mathrm{bA}}$ \\
0.001 & $44.07 \pm 0.07^{\mathrm{cA}}$ & $44.12 \pm 0.37^{\mathrm{bA}}$ \\
\hline
\end{tabular}

Values are presented as $\bar{x} \pm S E M$; Means with similar lowercase superscript alphabet within the same column are not significantly different (One-Way ANOVA followed by Tukey's test; 
$\mathrm{p}>0.05$ ), while values with similar uppercase superscript alphabet across the same row are not significantly different at $\alpha_{0.05}$ (Unpaired student t-test; $\mathrm{p}>0.05$ ).

These results indicate significant potentiation of catalase activity, and therefore, it is suggestive that the Phytexponent can enhance endogenous antioxidant enzymes, thus aiding remediation of oxidative stress and associated maladies (72).

\subsection{Qualitative phytochemical composition of the Phytexponent}

The medicinal value of medicinal plants is linked with the presence of secondary metabolites, the phytochemicals, synthesized by these plants $(15,78,79)$. In this study, the qualitative phytochemical composition of the Phytexponent was determined. The results revealed the presence of flavonoids, phenols, alkaloids, glycosides, tannins, among other pharmacologically important compounds (Table 6).

Table 6: qualitative phytochemical composition of the Phytexponent

\begin{tabular}{ll}
\hline Phytochemicals & Inference \\
\hline Flavonoids & + \\
Alkaloids & + \\
Phenols & + \\
Glycosides & + \\
Steroids & + \\
Terpenoids & + \\
Tannins & + \\
Saponins & + \\
Anthraquinones & - \\
\hline
\end{tabular}

+: Present; -; Absent

The role of medicinal plant phytochemicals in the promotion of health has been extensively deciphered (80-83). The presence of antioxidant compounds, including flavonoids, phenols, tannins, among other phytochemicals in the Phytexponent, explains its antioxidant and antiinflammatory efficacy reported in this study $(2,72,84-86)$. It is suggestive that these phytocompounds either singly or in synergy can quench oxidative stress and modulate the body's immune response, thus modulating pathologic inflammatory evocation $(2,85)$. 


\section{Conclusions and recommendations}

Based on the findings reported in this study, the Phytexponent has in vitro antioxidant and antiinflammatory activities. Furthermore, the Phytexponent has anti-inflammatory and antioxidant associated phytochemicals. Therefore, the Phytexponent may be potential source of antioxidative and anti-inflammatory molecules of pharmacologic significance. This study recommends further studies aimed at isolating bioactive compounds responsible for the reported activities. Moreover, in vivo anti-inflammatory studies should be done to determine whether the reported findings are replicable in in vivo setting. Furthermore, the specific mode(s) through which the Phytexponent exerts its bioactivity should be established.

\section{Conflict of Interest}

The authors declare that there is no conflict of interest whatsoever regarding this study.

\section{Data availability}

All data is included within the manuscript, and any further information is available from the author upon request.

\section{Funding}

This study did not receive any grant from any funding institution in the public or private sector.

\section{Acknowledgments}

The authors wish to acknowledge the Directorate of Research, Mount Kenya University, for availing laboratory space and equipment for this study. Mr. John Nzivo Mount Kenya University (School of Pharmacy) is acknowledged for his technical assistance.

\section{References}

1. Medzhitov R. Origin and physiological roles of inflammation. Nature. 2008;454(7203):428-35. 
2. Arulselvan P, Fard MT, Tan WS, Gothai S, Fakurazi S, Norhaizan ME, et al. Role of Antioxidants and Natural Products in Inflammation. Oxid Med Cell Longev. 2016;2016.

3. Allegra M. Antioxidant and anti-inflammatory properties of plants extract. Antioxidants. 2019;8(11).

4. Ghasemian M, Owlia S, Owlia MB. Review of Anti-Inflammatory Herbal Medicines. Vol. 2016, Advances in Pharmacological Sciences. 2016.

5. Diaz P, Jeong SC, Lee S, Khoo C, Koyyalamudi SR. Antioxidant and anti-inflammatory activities of selected medicinal plants and fungi containing phenolic and flavonoid compounds. Chinese Med (United Kingdom). 2012;7:12361-7.

6. Sai U, Tan BWQ, Vellayappan BA. Redox Biology ROS and the DNA damage response in cancer. Redox Biol [Internet]. 2018;(October):101084. Available from: https://doi.org/10.1016/j.redox.2018.101084

7. Moriasi G, Ireri A, Ngugi MP. In Vitro Antioxidant Activities of the Aqueous and Methanolic Stem Bark Extracts of Piliostigma thonningii ( Schum .). J Evidence-Based Integr Med. 2020;25:1-9.

8. Farmer EE, Mueller MJ. ROS-Mediated Lipid Peroxidation and RES-Activated Signaling. Annu Rev Plant Biol. 2013;64(1):429-50.

9. Maria C, Volpe O, Henrique P, Martins P, Nogueira-machado JA. Cellular death , reactive oxygen species ( ROS ) and diabetic complications. 2018;

10. True B-L, Dreisbach RH, True B-L, Dreisbach RH. Analgesics, antipyretics, and antiinflammatory agents. Dreisbach's Handb POISONING. 2013;(4):367-78.

11. Carter GT, Duong V, Ho S, Ngo KC, Greer CL, Weeks DL. Side effects of commonly prescribed analgesic medications. Phys Med Rehabil Clin N Am. 2014;25(2):457-70.

12. Süleyman H, Demircan B, Karagöz Y. Anti-inflammatory and side effects of cyclooxygenase inhibitors. Pharmacological Reports. 2007.

13. Bacchi S, Palumbo P, Sponta A, Coppolino MF. Clinical Pharmacology of NonSteroidal Anti-Inflammatory Drugs: A Review. Antiinflamm Antiallergy Agents Med Chem. 2012;11(1):52-64.

14. Andreicut AD, Pârvu AE, Mot AC, Pârvu M, Fodor EF, Cătoi AF, et al. Phytochemical analysis of anti-inflammatory and antioxidant effects of Mahonia aquifolium flower and fruit extracts. Oxid Med Cell Longev. 2018;2018.

15. Upadhyay S, Dixit M. Role of polyphenols and other phytochemicals on molecular signaling. Oxid Med Cell Longev. 2015;2015.

16. Reuter S, Gupta SC, Chaturvedi MM, Aggarwal BB. Oxidative stress, inflammation, and cancer: How are they linked? Free Radic Biol Med [Internet]. 2010;49(11):160316. Available from: http://dx.doi.org/10.1016/j.freeradbiomed.2010.09.006

17. Akram M, Hamid A, Khalil A, Ghaffar A, Tayyaba N, Saeed A, et al. Review on medicinal uses, pharmacological, phytochemistry and immunomodulatory activity of plants. International Journal of Immunopathology and Pharmacology. 2014.

18. Martins N, Petropoulos S, Ferreira ICFR. Chemical composition and bioactive compounds of garlic (Allium sativum L.) as affected by pre- and post-harvest conditions: 
A review. Food Chemistry. 2016.

19. Rastogi S, Pandey MM, Rawat AKS. Traditional herbs: a remedy for cardiovascular disorders. Phytomedicine. 2016;

20. Sharifi-Rad M, Mnayer D, Morais-Braga MFB, Carneiro JNP, Bezerra CF, Coutinho HDM, et al. Echinacea plants as antioxidant and antibacterial agents: From traditional medicine to biotechnological applications. Phytotherapy Research. 2018.

21. Š Sutovská M, Capek P, Kazimierová I, Pappová L, Jošková M, Matulová M, et al. Echinacea complex - Chemical view and anti-asthmatic profile. J Ethnopharmacol. 2015;

22. Capek P, Šutovská M, Kocmálová M, Fraňová S, Pawlaczyk I, Gancarz R. Chemical and pharmacological profiles of Echinacea complex. Int J Biol Macromol. 2015;

23. Cichello SA, Yao Q, He XQ. Proliferative activity of a blend of Echinacea angustifolia and Echinacea purpurea root extracts in human vein epithelial, HeLa, and QBC-939 cell lines, but not in Beas-2b cell lines. J Tradit Complement Med. 2016;

24. Maghrani M, Lemhadri A, Zeggwagh NA, El Amraoui M, Haloui M, Jouad H, et al. Effects of an aqueous extract of Triticum repens on lipid metabolism in normal and recent-onset diabetic rats. J Ethnopharmacol. 2004;90(2-3):331-7.

25. Al-Snafi AE. Chemical constituents and pharmacological importance of Agropyron repens -A review. Res J Pharmacol Toxicol [Internet]. 2015;02(2):1. Available from: www.asdpub.com/index.php/rjpt\%0Awww.ijpt.org\%0Awww.asdpub.com/index.php/rj $\mathrm{pt}$

26. Wong KL, Wong RNS, Zhang L, Liu WK, NG TB, Shaw PC, et al. Bioactive proteins and peptides isolated from Chinese medicines with pharmaceutical potential. Chinese Med (United Kingdom). 2014;9(1).

27. Koike A, Barreira JCM, Barros L, Santos-Buelga C, Villavicencio ALCH, Ferreira ICFR. Edible flowers of Viola tricolor L. as a new functional food: Antioxidant activity, individual phenolics and effects of gamma and electron-beam irradiation. Food Chem [Internet]. 2015;179:6-14. Available from: http://dx.doi.org/10.1016/j.foodchem.2015.01.123

28. Satyal P, Shrestha S, Setzer WN. Composition and bioactivities of an (E)- $\beta$-farnesene chemotype of chamomile (matricaria chamomilla) essential oil from Nepal. Nat Prod Commun. 2015;10(8):1453-7.

29. Jang MH, Piao XL, Kim JM, Kwon SW, Park JH. Inhibition of cholinesterase and amyloid-\&bgr; aggregation by resveratrol oligomers from Vitis amurensis. Phyther Res [Internet]. 2008;22(4):544-549. Available from: http://www3.interscience.wiley.com/journal/117934759/abstract

30. Cvetanović A, Švarc-Gajić J, Mašković P, Savić S, Nikolić L. Antioxidant and biological activity of chamomile extracts obtained by different techniques: Perspective of using superheated water for isolation of biologically active compounds. Ind Crops Prod. 2015;65:582-91.

31. Sakat SS, Juvekar AR, Gambhire MN. In-vitro antioxidant and anti-inflammatory activity of methanol extract of Oxalis corniculata linn. Int $\mathrm{J}$ Pharm Pharm Sci. 2010;2(1):146-55. 
32. Rastogi S, Iqbal MS, Ohri D. In vitro study of anti-inflammatory and antioxidant activity of some medicinal plants and their interrelationship. Asian J Pharm Clin Res. 2018;11(4):195-202.

33. Mizushima Y, Kobayashi M. Interaction of anti-inflammatory drugs with serum proteins, especially with some biologically active proteins. J Pharm Pharmacol. 1968;20(3):169-73.

34. Brand-Williams, W; Cuvelier ME, Berset C. Use of a Free Radical Method to Evaluate Antioxidant Activity. 1995;30:25-30.

35. Ruiz-Terán F, Medrano-Martínez A, Navarro-Ocaña A. Antioxidant and free radical scavenging activities of plant extracts used in traditional medicine in Mexico. African $\mathrm{J}$ Biotechnol. 2008;7(12):1886-93.

36. Klein SM, Cohen G, Cederbaum AI. Production of formaldehyde during metabolism of dimethyl sulfoxide by hydroxy. Vol. 20, Biochemistry. 1981. p. 6006-12.

37. Aebi H. [13] Catalase in Vitro. Methods Enzymol. 1984;105(C):121-6.

38. Atawodi SE. Evaluation of the Hypoglycemic, Hypolipidemic and Antioxidant Effects of Methanolic Extract of "Ata-Ofa" Polyherbal Tea (APolyherbal) in Alloxan-Induced Diabetic Rats. Drug Invent Today. 2001;3(11):270-6.

39. Moriasi GA, Ireri AM, Ngugi MP. In Vivo Cognitive-Enhancing, Ex Vivo Malondialdehyde-Lowering Activities and Phytochemical Profiles of Aqueous and Methanolic Stem Bark Extracts of Piliostigma thonningii (Schum.). Int J Alzheimers Dis. 2020;2020.

40. Moriasi G, Ireri A, Ngugi M. Cognitive-Enhancing, Ex Vivo Antilipid Peroxidation and Qualitative Phytochemical Evaluation of the Aqueous and Methanolic Stem Bark Extracts of Lonchocarpus eriocalyx (Harms.). Lorigan G, editor. Biochem Res Int [Internet]. $2020 \quad$ Oct 1;2020:1-16. Available from: https://www.hindawi.com/journals/bri/2020/8819045/

41. Wang QS, Yang L, Cui WY, Chen L, Jiang YH. Anti-inflammatory and anti-nociceptive activities of methanol extract from aerial part of Phlomis younghusbandii Mukerjee. PLoS One. 2014;9(3):3-9.

42. Madubuike KG, Yusuf NO, Robinson ES. Evaluation of the in vitro and in vivo antioxidant potentials of Jatropha tanjorensis methanolic leaf extract. Int J Pharmacogn Phytochem Res. 2015;7(4):648-52.

43. Thanh TB, Duc LV, Thanh HN, Tien VN. In vitro antioxidant and anti-inflammatory activities of isolated compounds of ethanol extract from Sanchezia speciosa Leonard's leaves. J Basic Clin Physiol Pharmacol. 2017;28(1):79-84.

44. Gião MS, Pestana D, Faria A, Guimarães JT, Pintado ME, Calhau C, et al. Effects of extracts of selected medicinal plants upon hepatic oxidative stress. J Med Food. 2010;13(1):131-6.

45. Damodaran S. Protein: Denaturation. In: Handbook of Food Science, Technology, and Engineering - 4 Volume Set. 2005.

46. Huynh K, Partch CL. Analysis of protein stability and ligand interactions by thermal shift assay. Curr Protoc protein Sci. 2015; 
47. Bischof JC, He X. Thermal stability of proteins. Annals of the New York Academy of Sciences. 2006.

48. D’Imprima E, Floris D, Joppe M, Sánchez R, Grininger M, Kühlbrandt W. Protein denaturation at the air-water interface and how to prevent it. Elife. 2019;

49. Chandra S, Chatterjee P, Dey P, Bhattacharya S. Evaluation of in vitro antiinflammatory activity of coffee against the denaturation of protein. Asian Pac J Trop Biomed. 2012;

50. Jangle PP and SN. Evaluation of in vitro Anti-inflammatory Activity of Herbal Preparation, a Combination of Four Medicinal Plants. Int J Basic Appl Med Sci. 2012;

51. Duganath N, Kumar SR, Kumanan R, Jayaveera KN. Evaluation of anti-denaturation property and anti-oxidant activity of traditionally used medicinal plants. Int J Pharma Bio Sci. 2010;1(2).

52. Govindappa M. Antimicrobial, antioxidant and in vitro anti-inflammatory activity of ethanol extract and active phytochemical screening of Wedelia trilobata (L.) Hitchc. J Pharmacogn ... [Internet]. 2011;3(April):43-51. Available from: http://www.academicjournals.org/JPP/PDF/Pdf2011/April/Govindappa et al.pdf

53. Fischer $R$, Maier $O$. Interrelation of oxidative stress and inflammation in neurodegenerative disease: Role of TNF. Oxid Med Cell Longev. 2015;2015.

54. Oschman JL, Chevalier G, Brown R. The effects of grounding (earthing) on inflammation, the immune response, wound healing, and prevention and treatment of chronic inflammatory and autoimmune diseases. J Inflamm Res. 2015;8:83-96.

55. McPhee SJ, Papadakis MA. Current Medical Diagnosis and Treatment, 2010 (49th Edition). Curr Med Diagnosis Treat 2010, 49th Ed [Internet]. 2010;569-73. Available from:

http://site.ebrary.com.proxy.campbell.edu/lib/campbellu/docDetail.action?docID=1035 5332

56. Zhang Q, Africa I. Policy Review. 2018;1(1):11-3.

57. Qi Z. WHO Traditional Medicine Strategy 2014-2023 $\square$ Background and progress in the last decade. 2015;(March).

58. WHO. WHO Traditional Medicine Strategy 2002-2005. World Heal Organ. 2005;1-60.

59. World Health Organization (WHO). WHO Traditional Medicine Strategy 2014-2023. World Heal Organ. 2013;

60. Pallio G, Irrera N, Pizzino G, Bitto A, Cucinotta M, Altavilla D, et al. Oxidative Stress: Harms and Benefits for Human Health. Oxid Med Cell Longev. 2017;2017:1-13.

61. Simpson T, Pase M, Stough C. Bacopa monnieri as an Antioxidant Therapy to Reduce Oxidative Stress in the Aging Brain . Evidence-Based Complement Altern Med. 2015;2015:1-9.

62. Ozcan T, Akpinar-Bayizit A, Yilmaz-Ersan L, Delikanli B. Phenolics in Human Health. Int J Chem Eng Appl. 2014;

63. Augustin JM, Kuzina V, Andersen SB, Bak S. Molecular activities, biosynthesis and evolution of triterpenoid saponins. Phytochemistry. 2011. 
64. Moriasi GA, Ireri AM, Ngugi MP. In Vivo Cognitive-Enhancing, Ex Vivo Malondialdehyde-Lowering Activities and Phytochemical Profiles of Aqueous and Methanolic Stem Bark Extracts of Piliostigma thonningii (Schum.). Panza F, editor. Int J Alzheimer\&\#x2019;s Dis. 2020;2020:1367075.

65. Baierle M, Nascimento SN, Moro AM, Brucker N, Freitas F, Gauer B, et al. Relationship between inflammation and oxidative stress and cognitive decline in the institutionalized elderly. Oxid Med Cell Longev. 2015;2015.

66. Korkina LG. Phenylpropanoids as naturally occurring antioxidants: From plant defense to human health. Cell Mol Biol. 2007;53(1):15-25.

67. Blois MS. Antioxidant determinations by the use of a stable free radical [10]. Nature. 1958;181(4617):1199-200.

68. Apak R, Gorinstein S, Böhm V, Schaich KM, Özyürek M, Güçlü K. Methods of measurement and evaluation of natural antioxidant capacity/activity (IUPAC Technical Report). Pure Appl Chem [Internet]. 2013;85(5):957-98. Available from: https://www.degruyter.com/view/j/pac.2013.85.issue-5/pac-rep-12-07-15/pac-rep-1207-15.xml

69. Doreddula SK, Bonam SR, Gaddam DP, Desu BSR, Ramarao N, Pandy V. Phytochemical analysis, antioxidant, antistress, and nootropic activities of aqueous and methanolic seed extracts of ladies finger (Abelmoschus esculentus L.) in Mice. Sci World J. 2014;2014(October).

70. Fidrianny I, Budiana W, Ruslan K. Antioxidant activities of various extracts from ardisia sp leaves using dpph and cuprac assays and correlation with total flavonoid, phenolic, carotenoid content. Int J Pharmacogn Phytochem Res. 2015;7(4):859-65.

71. Halliwell B, Gutterdige JMC. Free Radicals in Biology \& Medicine. Oxford Univ Press. 2015;5:961.

72. Huang D. Dietary antioxidants and health promotion. Antioxidants. 2018;7(1):7-9.

73. Niki E, Yoshida Y, Saito Y, Noguchi N. Lipid peroxidation: Mechanisms, inhibition, and biological effects. Biochemical and Biophysical Research Communications. 2005.

74. Mladěnka P, Zatloukalová L, Filipskỳ T, Hrdina R. Cardiovascular effects of flavonoids are not caused only by direct antioxidant activity. Free Radical Biology and Medicine. 2010.

75. Moorhouse PC, Grootveld M, Halliwell B, Quinlan JG, Gutteridge JMC. Allopurinol and oxypurinol are hydroxyl radical scavengers. FEBS Lett. 1987;

76. Lipinski B. Hydroxyl radical and its scavengers in health and disease. Oxidative Medicine and Cellular Longevity. 2011.

77. Gligorovski S, Strekowski R, Barbati S, Vione D. Environmental Implications of Hydroxyl Radicals $(\bullet \mathrm{OH})$. Chem Rev. 2015;

78. Virgili F, Marino M. Regulation of cellular signals from nutritional molecules: a specific role for phytochemicals, beyond antioxidant activity. Free Radic Biol Med [Internet]. 2008;45(9):1205-16. Available from: http://dx.doi.org/10.1016/j.freeradbiomed.2008.08.001 
79. Angeline A, Phillip O, Lawrence M, Isholan Ishmael, Regina N,; Charles O, and Sylvia A. Trends in Phytochemical Research (TPR). TprIau-ShahroodAcIr [Internet]. 2017;1(4):169-74. Available from: http://tpr.iaushahrood.ac.ir/article_531709_ca41f3d55a966df0922faf00e511f085.pdf

80. Kurmukov AG. Phytochemistry of medicinal plants. Med Plants Cent Asia Uzb Kyrg. 2013;1(6):13-4.

81. Phillipson JD. Phytochemistry and medicinal plants. Phytochemistry. 2001;

82. Ashok P, Upadhyaya K. Tannins are Astringent. J Pharmacogn Phytochem. 2012;

83. Solowey E, Lichtenstein M, Sallon S, Paavilainen H, Solowey E, Lorberboum-Galski H. Evaluating medicinal plants for anticancer activity. Sci World J. 2014;2014.

84. Sardesai VM. Role of Antioxidants in Health Maintenance. Nutr Clin Pract. 1995;10(1):19-25.

85. Zarkovic N. Antioxidants and second messengers of free radicals. Antioxidants. 2018;7(11):10-3.

86. Lourenço SC, Moldão-Martins M, Alves VD. Antioxidants of natural plant origins: From sources to food industry applications. Molecules. 2019;24(22):14-6. 